\title{
Evaluation of Mechanical Properties of Damascus Steel
}

\author{
Adrián Židzik ${ }^{1}$, Zuzana Mital'ová ${ }^{1}$, František Botko ${ }^{1}$, Vladimír Simkulet ${ }^{1}$, \\ Dominika Botková $^{1,2}$, Dušan Mital ${ }^{1}$
${ }^{1}$ Faculty of Manufacturing Technolgies of Technical University of Košice with seat in Prešov, Bayerova 1, 08001 Prešov, Slovakia
${ }^{2}$ The Czech Academy of Sciences, Institute of Geonics, Studentska 1768, 70800 Ostrava - Poruba, Czech Republic

\begin{abstract}
This article deals with examination of the mechanical properties of Damascus steel. Damascus steel is steel used for blades or knives - similar to the past (Damascus steel was a type of steel used for blades in the Near East - made from wootz steel - imported from India). This steel is characterized by significant patterns. The aim of the present study is to point out the laborious method of Damascus production, and to compare the mechanical properties of the initial Damascus steel layers comparison with whole reference Damascus material steel itself.
\end{abstract}

Keywords - wootz, Damascus steel, mechanical properties, hardness, Charpy impact test

\section{Introduction}

Damascus steel (damascus, has typical carbon composition of about $1.5 \mathrm{wt} \%$ ) is a material with a characteristic internal structure / drawing, where layers of two, resp. several types of steel (or other metals) are present [1]. The layers are connected to each other by a blacksmith welding method.

DOI: $10.18421 /$ TEM104-17

https://doi.org/10.18421/TEM104-17

Corresponding author: Zuzana Mital'ová, Faculty of Manufacturing Technologies of Technical University of Košice with seat in Prešov.

Email: zuzana.mitalova@tuke.sk

Received: 02 June 2021.

Revised: 18 September 2021.

Accepted: 25 September 2021.

Published: 26 November 2021.

(c) Br-NC-ND C 2021 Adrián Židzik et al; published by UIKTEN. This work is licensed under the Creative Commons Attribution-NonCommercial-NoDerivs 4.0 License.

The article is published with Open Access at www.temjournal.com
After grinding, etching and polishing, a layered structure is created - the drawing (the appearance of the drawing depends on several factors, but the production technology also plays an important role) [2]. The combination of hard high carbon steel with tough low carbon steel will result in a fracture and wear resistant material. The disadvantage of damascus steel is its susceptibility to corrosion and maintenance (except for damascus steel produced by powder metallurgy technology). Initial mentions of damascus steel are recorded around the year $300 \mathrm{BC}$ (originally referred to as "wootz") [3], [4], [5]. The exact method of production is unknown, it is a mystery [6], [7]. Production by a nano-technological process is expected, which has not yet been clarified. High values of the mechanical properties of the damascus steel were provided by hollow carbon microfibers coated with iron carbide fibers. The steel was then exported to the Damascus shopping center in Syria, for further processing. Damascus steel arrived in European countries in the early Middle Ages. Damascus steel production technology was perfected by Japanese samurai sword makers in the $13^{\text {th }}$ century.

The production of patterned swords gradually declined until it completely disappeared around 1750 (the cause of the cessation of production is still unknown). Nowdays, additive manufacturing is possible to use for production of high-strength Damascus steel [8], [9]. An example of damascus steel used to be made a knife blade (Figure 1. and Figure 2.).

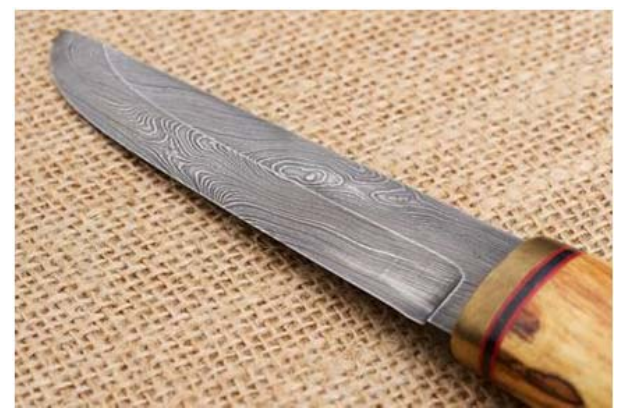

Figure 1. Damascus steel [10] 


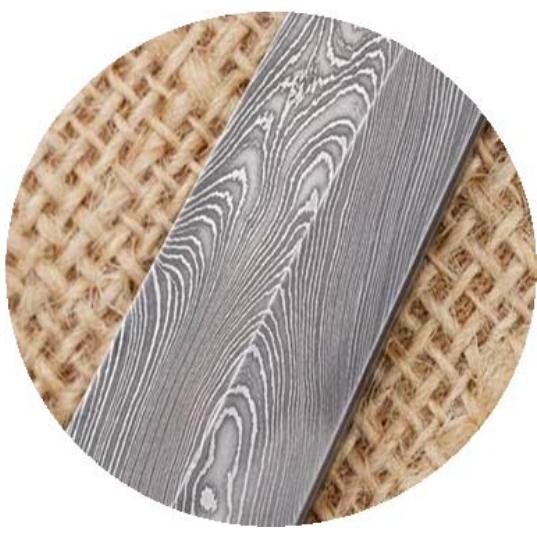

Figure 2. Detail - characteristic drawing on the blade surface [11]

Nowadays, groups of authors abroad, also at home in universities and research institutes, are assessing the properties of false Damascus steel. In relation to the choice of materials for the Damascus steel layers, the mechanical properties of the final product are different [12], [13]. The aim of the present study is to point out the laborious method of Damascus production, and to compare the mechanical properties of the primary components of Damascus Dsteel and the damascus steel itself. This is an assessment of the properties of the steels of the layers: EN ISO 90MnCrV8 / EN ISO 80NiCr11 and Damascus steel itself (resulting from the interleaving of layers of the two mentioned materials).

\section{Experimental Procedure}

Material: The experimental material was Damascus steel (300 layers) composed of a hard and tough component: Böhler K720 steel (designation according to EN ISO 90MnCrV8) / steel EN ISO $80 \mathrm{NiCr} 11$. Characteristics of selected steels: steel Böhler K720 (hard phase): tool steel resistant to dimensional changes, with forming temperature 1050-850 ${ }^{\circ} \mathrm{C}$, application: for cutting tools (dies, punches), tools for pressing, threading, tools for woodworking, gauges, moulds for plastics, machine knives for the paper / wood / steel industry (material composition and conditions of heat treatment are given in Table 1. and Table 2.). Characteristics of steel EN ISO 80CrNi11 (tough phase): resistance to etching of the resulting structure as light excel component. It is a steel alloy with a high hardenability, usable for flexible wear resistant tools (material composition is given in Table 3.).

Table 1. Material composition [14]

\begin{tabular}{|c|c|c|c|c|}
\hline$C[\%]$ & Si [\%] & $M n[\%]$ & $\operatorname{Cr}[\%]$ & $V[\%]$ \\
\hline 0.90 & 0.25 & 2.00 & 0.35 & 0.10 \\
\hline
\end{tabular}

Table 2. Heat treatment [14]

Annealing: $\mathrm{T}=680-720{ }^{\circ} \mathrm{C}$ (slow controlled cooling in furnace at a rate of 10 to $20^{\circ} \mathrm{C} / \mathrm{hr}$ down to approx. $600^{\circ} \mathrm{C}$, further cooling in air. Hardness after annealing: max. $220 \mathrm{HB}$.

Stress relieving: $T=$ approx. $650{ }^{\circ} \mathrm{C}$ (slow cooling in furnace, intended to relieve stresses set up by extensive machining, or in complex shapes. After through heating, hold in neutral atmosphere for 1-2 hours.

Hardening: $T=790-820{ }^{\circ} \mathrm{C}$ (oil, salt bath up to $20 \mathrm{~mm}$ thickness. Holding time after temperature equalization: 15 to 30 minutes. Obtainable hardness: 50-62 HRC).

Tempering: slow heating to tempering temperature immediately after hardening/time in furnace 1 hour for each $20 \mathrm{~mm}$ of workpiece thickness but at least 2 hours/cooling in air. For average hardness figures to be obtained please refer to the tempering chart. For certain cases we recommend to reduce tempering temperature and increase holding time.

Table 3. Material composition [14]

\begin{tabular}{|c|c|c|c|c|c|}
\hline$C[\%]$ & $M n[\%]$ & Si [\%] & $\operatorname{Cr}[\%]$ & Ni [\%] & S [\%] \\
\hline $0.74-0.8$ & $0.25-0.6$ & $<0.4$ & $0.2-0.5$ & $2.4-2.9$ & 0.025 \\
\hline
\end{tabular}

Preparation of experimental samples (experimental procedure of Damascus steel): The above-described steels were applied to the production of Damascus steel with the number of layers: 300 , Böhler K720 steel blank: 3 × 30 × $1000 \mathrm{~mm}$, steel blank EN ISO 80CrNil1: $1.6 \times 30 \times 1000 \mathrm{~mm}$ (hard / tough component ratio: $2 / 1$ ). A belt sander was applied to remove layers of oxides and impurities (the treatment will ensure the elimination of unwanted errors in the final appearance). The semi-finished products were divided into lengths of $100 \mathrm{~mm}$ and cleaned with a degreasing agent (Figure 3.). Subsequently, the material was placed on top of each other (the two mentioned layers alternated during folding: hard versus tough steel), clamped and welded by the method of shielded metal arc welding (SMAW) along the edges and in the middle, thus creating a packet (Figure 4.).

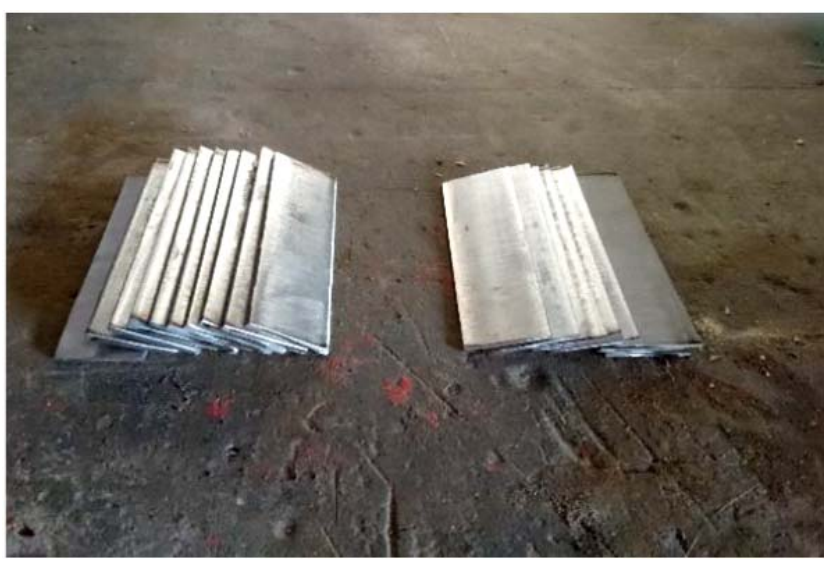

Figure 3. Bars $100 \mathrm{~mm}$ long (hard and toughness component) 


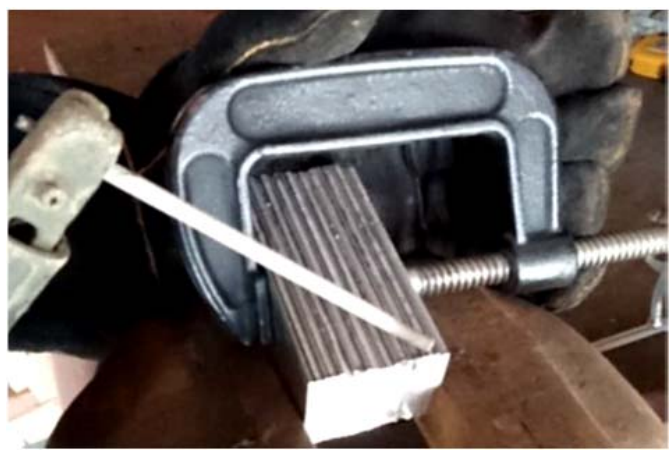

Figure 4. Package welding

After the package was made, the procedure was as follows:

1. heating to a temperature of approx. $800{ }^{\circ} \mathrm{C}$,

2. sprinkle with borax $-\mathrm{Na}_{2} \mathrm{~B}_{4} \mathrm{O}_{7}$ (an agent to help raise the temperature and dissolve unwanted oxides on the surface of the packet),

3. heating to a temperature $1100-1200{ }^{\circ} \mathrm{C}$,

4. forging (this is a manual forging, the blows must be fast and strong due to the cooling of the package),

5. sanding of the oxidized layer, immersion in hydrochloric acid - visibility of the pattern (Figure 5.).

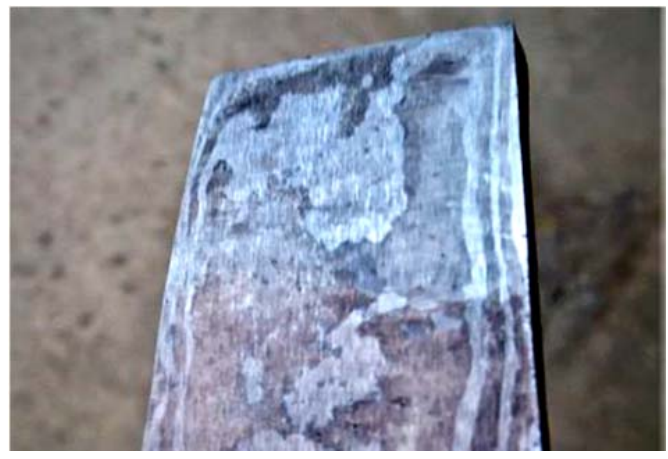

Figure 5. 20-layers damask made

Subsequently, the 20-layer Damascus was divided into 5 pieces $(6 \mathrm{~cm}$ long), oxides and impurities were removed from the Damascus. This was followed by re-welding into the package - following the procedure described in points 1 to 4 . The package then consisted of 5 pieces of 20-layer Damascus steel, thus obtaining 100 layers. This was followed by a repetition of the procedure - until the final rod with 300 layers was made (Figure 6.).

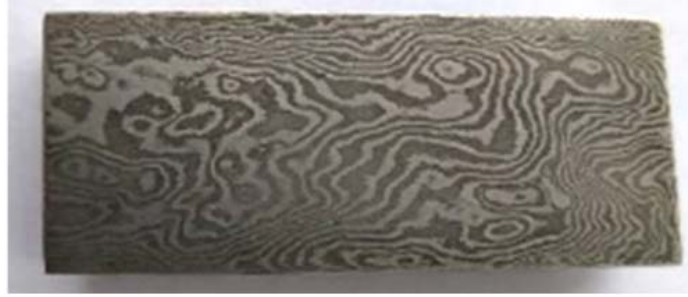

Figure 6. 300-layers damask made

\section{Hardness Measurement and Charpy Impact Test}

Measurement of the material toughness was performed (using a Charpy hammer, under laboratory conditions $T=20^{\circ} \mathrm{C}$ ), test specimens were made with a V-shaped notch $-2 \mathrm{~mm}$ deep, with an angle of $45^{\circ}$. Number of tested materials: 3 (original materials - components of Damascus steel: Böhler K720, EN ISO $80 \mathrm{CrNi11}+$ Damascus steel itself). Arrangement of fibres on Damascus steel samples - see Figure 7. (on the left, there is an image of the sample with a defect - a crack on the surface. In relation to the location of the crack on the surface of the sample, outside the notch, it can be stated that it does not affect the toughness value of the material). A Rockwell ISH-RSR400 INSIZE automatic digital hardness tester was used to measure the hardness of individual materials, consisting of a precision mechanism with optical and electrical systems. Applied method: HRC - Rockwell test (indentor: cone with apex angle $120^{\circ}$ ).

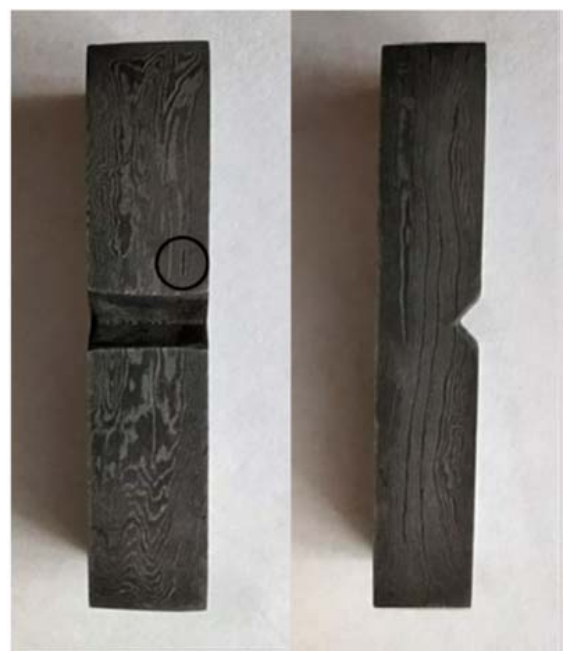

Figure 7. Sample for Charpy impact test (defect on the surface, outside of notch) / layers of test material

The place of measurement was determined randomly, repeatability of measurement on individual samples: $3 \mathrm{x}$. Before the measurement itself, it is necessary to adjust the sample by curing in a silicone potting mould. The samples were also examined on a scanning electron microscope $f$. Tescan, type: Mira 3 (before the actual observation they were cleaned in an ultrasonic bath). Samples 1 and 2 were subjected to EDX chemical composition analysis (to compare the values with the values given by the manufacturer). Measurement of hardness and toughness: characteristics of selected materials (sample 1 - sample 3: quenched at $800{ }^{\circ} \mathrm{C}$ and tempered at $100^{\circ} \mathrm{C}$ ): sample no. 1 - hard component (Böhler K720), sample no. 2 - resilient component EN ISO 80NiCr11, sample no. 3 - Damascus (ratio of hard / resilient component - 2:1), layers 300 . 
Table 4. Measured values of absorbed energy KC [J]and hardness HRC

\begin{tabular}{|c|c|c|}
\hline Sample no. & KC [J] & $\begin{array}{c}\text { Average hardness HRC } \\
\text { (place 1/ place 2 / place 3) }\end{array}$ \\
\hline Sample 1 & 2,48 & $64(64 / 63 / 64)$ \\
\hline Sample 2 & 58,88 & $42(43 / 41 / 42)$ \\
\hline Sample 3 & 10,72 & $55(55 / 56 / 53)$ \\
\hline
\end{tabular}

The measured values of hardness and toughness of individual samples are shown in Table 4. and Figure 8., Figure 9. Average value of hardness of sample no. 3: Damascus steel is $55 \mathrm{HRC}$ (for comparison, the hardness value of sample no. 1 is equal to $64 \mathrm{HRC}$ ). The hardness of Damascus steel is thus at the level of $86 \%$ of the hardness of the hard phase. The value of the energy consumed to break the sample in sample no. 3 is $18 \%$ of the $\mathrm{KC}$ value of the tough sample (for the tough component the $\mathrm{KC}$ value was measured to be $58.88 \mathrm{~J}$ ).

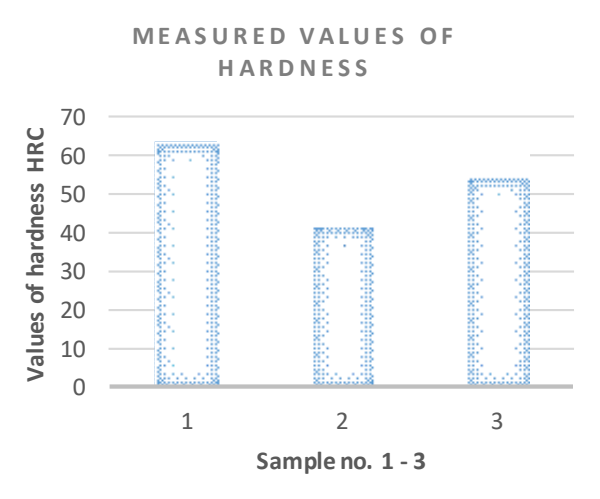

Figure 8. Measured hardness values of materials samples $1-3$

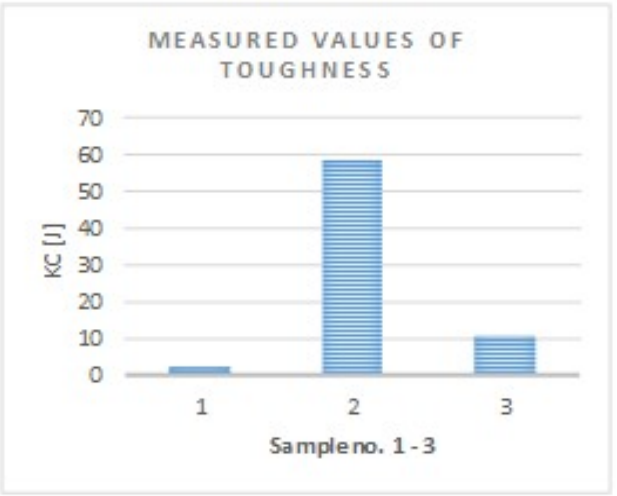

Figure 9. Measured values of toughness of materials samples $1-3$

Figure 10., Figure 11. and Figure 12. show the fracture surfaces of samples $1 / 2 / 3$. The least shaped fracture surface was observed on sample 1, where brittle fissile fracture facets are visible. This sample also showed the lowest toughness values $(2.48 \mathrm{~J})$ and the highest hardness (average hardness value $64 \mathrm{HRC}$ ). The most articulated fracture area was observed in sample number 2, which documents the sites of more ductile mixed intercrystalline and transcrystalline fracture with a higher number of pit fractures than in sample 1 (which is also predicted by the results of the previous toughness and hardness test of this sample, Table 4.). In the case of sample 3, a Damascus steel composed of sequentially interleaving of the materials of samples 1 and 2, this is a mixed fracture surface: intercrystalline and transcrystalline failure. In the examined sample 2, the EDX analysis of the chemical composition was also evaluated, Figure 13. The carbon recalculation was suspended due to greater contamination from the environment around the microscope chamber. The results confirmed the content of the elements within the range specified by the manufacturer.

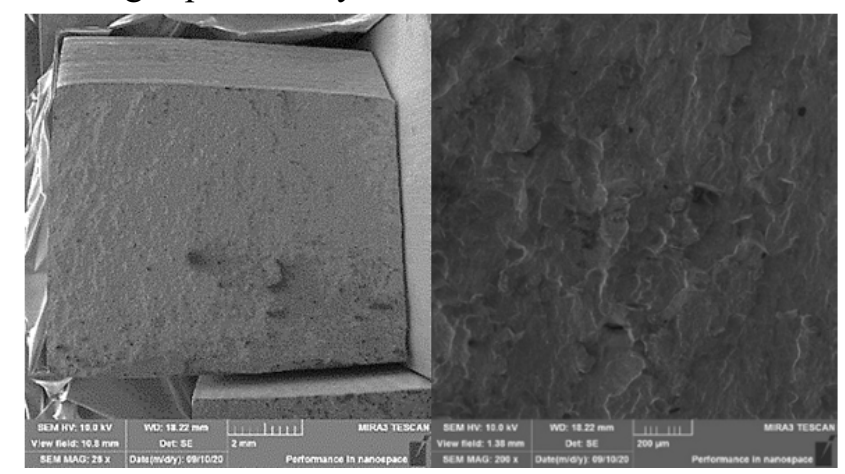

Figure 10. Views of the fracture surface of sample no. 1 (magnification: 26x - left side, magnification $200 x$-right side)

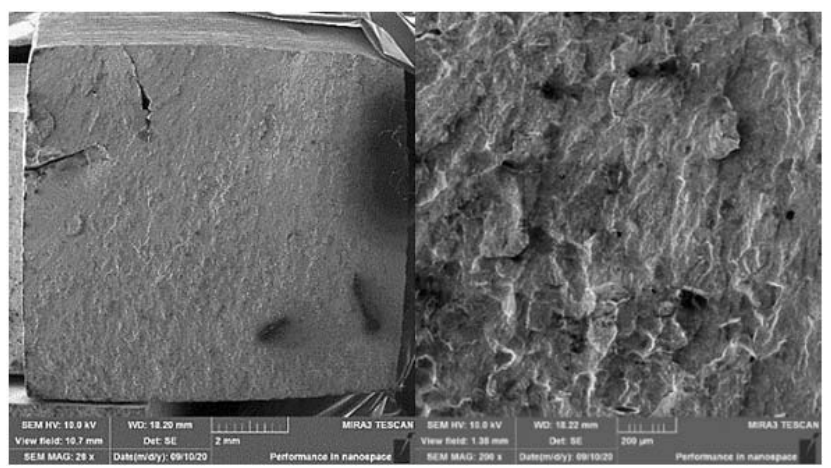

Figure 11. Views of the fracture surface of sample no. 2 (magnification: 26x - left side, magnification $200 x$-right side)

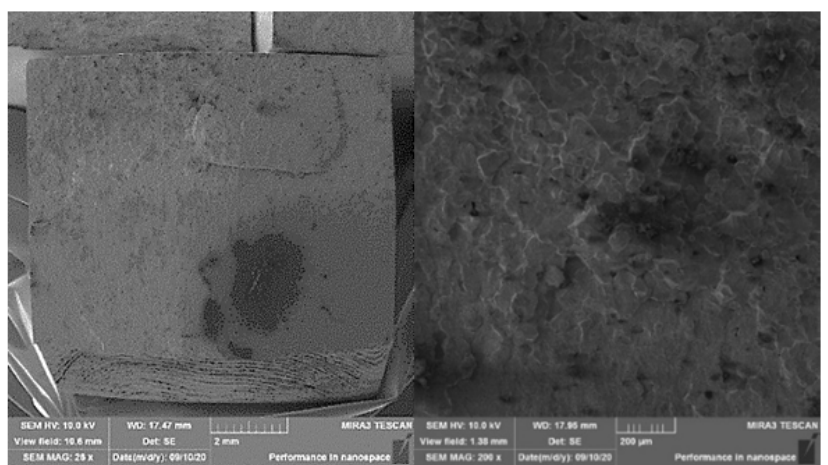

Figure 12. Views of the fracture surface of sample no. 3 (magnification: $26 x$ - left side, magnification $200 x$-right side)

In the examined sample 2, the EDX analysis of the chemical composition was also evaluated, Figure 13. (examined place - Figure 14.). The carbon recalculation was suspended due to greater contamination from the environment around the microscope chamber. The results confirmed the content of the elements within the range specified by the manufacturer. 


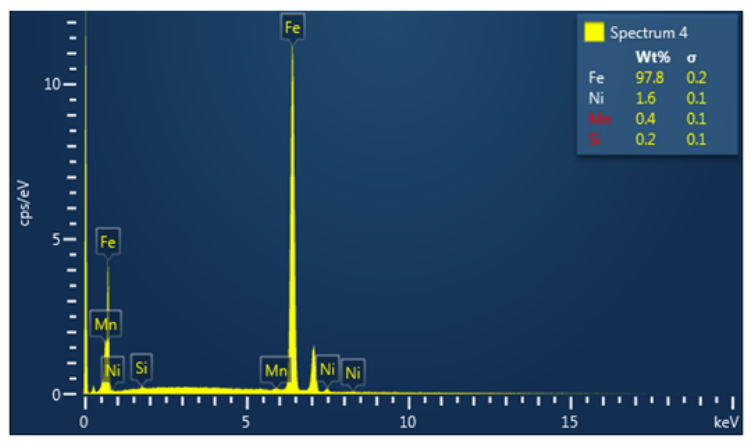

Figure 13. Example of EDX analysis of sample 2 (EN ISO 80NiCr11)

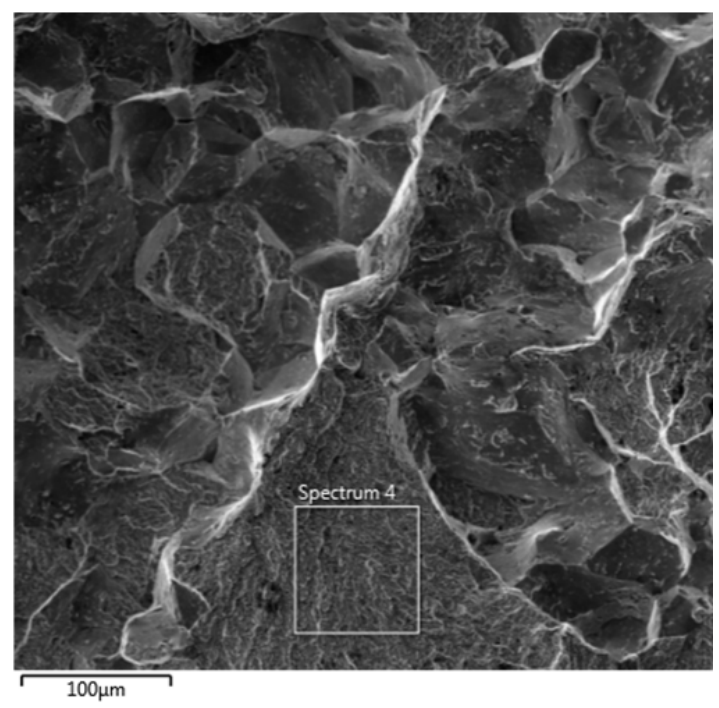

Figure 14. Sample 2: examined place (EN ISO 80 NiCr11)

\section{Conclusion}

The method of welding forging, where are combined two different layer materials - tough and hard, the new material designed and is named/consider as false Damascus steel. The subject of the presented article was to point out the timeconsuming / laborious method of Damascus steel production, and to examine the mechanical properties of the resulting package (by comparing it with the mechanical properties of its individual components). The values of mechanical properties of Damascus steel themselves are in the range of values of mechanical properties of individual components (hard component - steel EN ISO $90 \mathrm{MnCrV} 8$ and tough component - steel EN ISO 80NiCr11). The recorded fracture surfaces of the materials have a characteristic relief - in relation to the toughness of the individual components being compared.

\section{Acknowledgement}

This work was supported by the project KEGA 032TUKE-4/2021 (Transfer and implementation of knowledge in the field of energy beam technologies into study programs of technical secondary schools supporting dual education).

\section{References}

[1]. Taleff, E. M., Bramfitt, B. L., Syn, C. K., Lesuer, D. R., Wadsworth, J., \& Sherby, O. D. (2001). Processing, structure, and properties of a rolled, ultrahigh-carbon steel plate exhibiting a damask pattern. Materials Characterization, 46(1), 11-18.

[2]. Nazarenko, V. R., Bondarenko, L. I., Yankovskii, V. F., \& Dolginskaya, M. A. (1989). The method of production of damask steel. Metal Science and Heat Treatment, 31(9), 712-716.

[3]. Verhoeven, J. D., Pendray, A. H., \& Dauksch, W. E. (2004). The continuing study of damascus steel: Bars from the alwar armory. Jom, 56(9), 17-20.

[4]. Perttula, J. (2001). Reproduced wootz Damascus steel. Scandinavian journal of metallurgy, 30(2), 6568.

[5]. Verhoeven, J. D., Baker, H. H., Peterson, D. T., Clark, H. F., \& Yater, W. M. (1990). Damascus steel, part III: the Wadsworth-Sherby mechanism. Materials Characterization, 24(3), 205-227.

[6]. Damascus Steel (2021). Retrieved from: https://engineering.purdue.edu/MSE/aboutus/gotmater ials/History/horning.html [accessed: 21 May 2021].

[7]. Smirnova Zhanna, V., Vaganova, O. I., Kutepova, L. I., Kuttepov, M. M., \& Chaykina Zh, V. (2020). Steel Heat Treatment Technology. International Journal, 8(5).

[8]. Balasubramanian, N. (2020). A legend reborn: Additive manufacturing creates Wootz-Damascus steel. MRS Bulletin, 45(9), 685-685.

[9]. Kürnsteiner, P., Wilms, M. B., Weisheit, A., Gault, B., Jägle, E. A., \& Raabe, D. (2020). High-strength Damascus steel by additive manufacturing. Nature, 582(7813), 515-519.

[10]. Traditional handmade Finnish knife with the abstract wave pattern of damascus steel and wooden handle over an old sack background (2020). Retrieved from:

https://www.123rf.com/photo 51042014 traditionalhandmade-finnish-knife-with-the-abstract-wavepattern-of-damascus-steel-and-wooden-handl.html [accessed: 25 May 2021]

[11]. What is Damascus steel? (2021). Retrieved from: https://www.srcutleryindustry.com/what-is-damascussteel/?v=13dd621f 2711 [accessed: 14 April 2021]

[12]. Mintách, R., Nový, F., Bokůvka, O., \& Chalupová, M. (2012). Impact strength and failure analysis of welded Damascus steel. Materials Engineering, 19, 22-28.

[13]. Sukhanov, D. A., Arkhangelsky, L. B., \& Plotnikova, A. N. (2017, February). Damascus steel ledeburite class. In IOP Conference Series: Materials Science and Engineering (Vol. 175, No. 1, p. 012017). IOP Publishing.

[14]. Böhler - product description (2021). Retrieved from: https://www.bohler-edelstahl.com/en/products/k720/ [accessed: 20 May 2021] 